\section{Ultimate reliability}

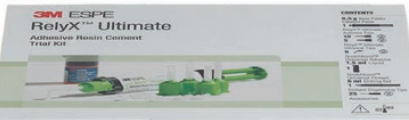

3M ESPE

RelyX $X^{\mathrm{TM}}$ Ultimate

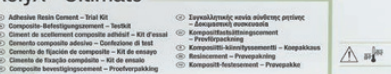

ac i
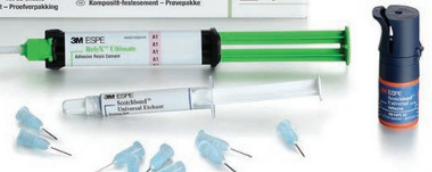

RelyX Ultimate adhesive resin cement from 3M Oral Care provides high bond strength for ultimate reliability.

Its almost natural fluorescence and high colour stability means RelyX Ultimate

adhesive resin cement can help you achieve a highly aesthetic result. This material also offers very easy mixing and handling due to optimised rheology.

Furthermore, working with Scotchbond Universal adhesive from 3M Oral Care, RelyX Ultimate adhesive resin cement requires less time to pre-treat restoration surfaces. It achieves full bond strength in fewer working steps, and has stronger or comparable initial and long-term bond strength on tooth structure, versus many leading competitive cements.

Contact the knowledgeable team today to find out more about RelyX Ultimate adhesive resin cement from $3 \mathrm{M}$ Oral Care.

For more information, call 0845602 5094 or visit www.3m.co.uk/oralcare.

$3 \mathrm{M}$, Scotchbond and RelyX are trademarks of the $3 \mathrm{M}$ Company.

\title{
No drying cycle, long-term service and sustainability
}

In January 2018 CPAC Equipment, Inc. is launching their new RapidHeat Pro11 HighCapacity Table-Top Sterilizer.

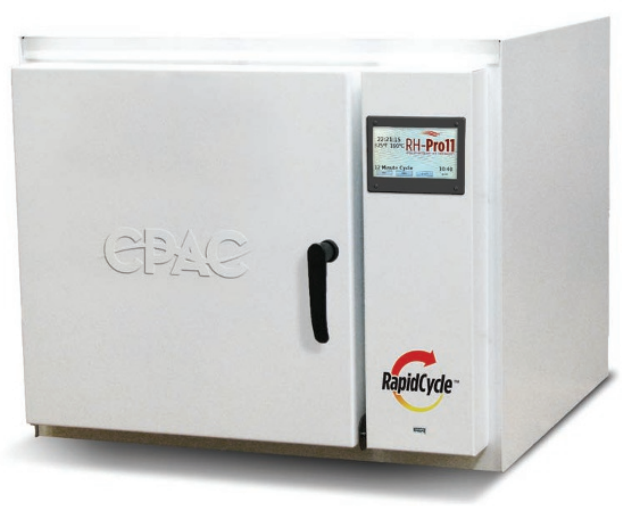

Advanced engineering enables the Pro11 to compete with the industry's popular table-top steam sterilisers with 50\% more capacity. The Pro11 uses the company's 'High-Velocity Hot Air' RapidHeat technology to perform a complete cycle in as little as six minutes. As no water or steam is used, the Pro11 has no drying cycle, requires very little maintenance, and comes with a standard three-year parts and labour warranty.

The Pro11 RapidHeat Tehcnology has been designed with long-term service and environmental sustainability - with independent laboratory testing confirming $85 \%$ less energy used per sterilisation cycle than comparable steam sterilisers. In addition, the same tests concluded that the RapidHeat Technology's waterless sterilisation environment does not contribute to instrument corrosion that has been proven to be common with steam sterilisation.

For more information email dbkaer@cpac. com or visit www.cpacequipment.com.

\section{Lightweight, powerful motor}

The NLZ electric motor, now available exclusively from A-dec, enables hasslefree treatments by putting complete control in your hands.

Made from lightweight titanium with balanced handling to ensure optimal ergonomics, it offers a durable and capable solution for your surgery with built-in LED daylight-quality illumination.

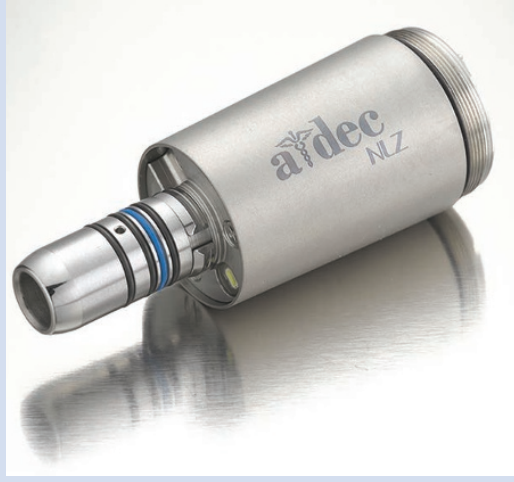

Combined with the A-dec deluxe touchpad's intuitive display and programmable memory, you can fully integrate your delivery system and place your focus where you need it - on your patients.

Programme the settings to match your preferences and do more in less time; the handpiece activates as you lift it from the holder so you can view display as needed. Enjoy a full range of speed with all the power you need.

It's also autoclavable, brushless and maintenance-free and is suitable for general restorative, prophylaxis and endodontic dentistry. Get greater precision and exceptional integration with the NLZ electric motor.

For more information about A-dec Dental UK, visit www.a-dec.co.uk or call 0800233285.

\section{Be on the safe side}

HR management does not tend to be an area of expertise that practice managers and principals are trained in, which can leave practices vulnerable to a range of legal issues.

Access to HR advice and representation from a dental specific lawyer is therefore imperative to dealing with disciplinary issues, dismissals, complaints and grievances and staff contracts.

Regulated by the Ministry of Justice and renowned for its knowledge of the sector, lawyers4dentists is one of the leading sources of legal advice in the profession for HR.

Using its unrivalled experience and insight, the team can act on your behalf to ensure that every aspect of HR management is handled to the letter. Should a claim be made in the employment tribunal, you can also rely on lawyers4dentists to handle this on your behalf, so get in touch now.

For more information call 0845345 5060, email info@4dentistsgroup.com or visit www.4dentistsgroup.com. 